Available online at GSC Online Press Directory

GSC Biological and Pharmaceutical Sciences

e-ISSN: 2581-3250, CODEN (USA): GBPSC2

(REVIEW ARTICLE)

\title{
Review on air purifier
}

Gowri Rajapandian *, Balaji Pandiyan, Leela Priyanka Chandrasekar, Kamalesh Raja Gopala Krishnan, Jenifer Sebastian, Monica Kesavel and Vinoth Sudharsan

Jaya College of Pharmacy, Thiruninravur, Tamil Nadu, India.

Publication history: Received on 14 March 2019; revised on 29 March 2019; accepted on 03 April 2019

Article DOI: https://doi.org/10.30574/gscbps.2019.7.1.0038

\begin{abstract}
Air contributes a prime role in recycling earth's most essential substances like carbon, since carbon sources encompass fossil fuel combustion and decayed matter of dead animals. Due to urbanization, population has been increased in cities inevitably which cause dreadful air pollution and pose a profound menace to public health and the environment. Outdoor air pollution has become panic in India, because Indian cities are some of the highest polluted cities in the world. Particulate pollution has significant worsen effects on human health. Diseases like asthma, chronic obstructive pulmonary disease (COPD), allergies and insomnia are caused or triggered by rising levels of air pollution. Sometimes the poor air quality leads to long-term health effects. Air purifiers occupy as prime factor to clean the air. It promotes our health against allergies, obnoxious odor and snoring. This review article discuss the causes of air pollution, need for air purifier and mechanism of working of air purifier.
\end{abstract}

Keywords: Air pollution; Insomnia; COPD

\section{Introduction}

Due to globalization and industrialization ecological life cycle has been affected which leads to increase in air pollution. The World Health Organization defines air pollution as "the presence of materials in the air in such concentration which are harmful to man and environment." A lucrative attention turned towards air purifiers for healthy indoor environment and human health against diseases. Air filtration is commonly suggested as a component of environmental control measures for patients with allergic respiratory disease.

\section{Causes of air pollution}

The various causes of air pollution are:

i. Burning of fossil fuels, petroleum, coal and wood in industries, automobiles, aircrafts, railways, thermal plants, agricultural burning, kitchens, etc. (Soot, $\mathrm{CO}_{2}$, $\mathrm{CO}$, nitrogen oxides, sulphur oxides).

ii. Metallurgical processing (mineral dust, fumes containing fluorides, sulphides and metallic pollutants like lead, chromium, nickel, beryllium, arsenic, vanadium, cadmium, zinc, mercury

iii. Chemical industries contribute to greater extent by pesticides, fertilizers, weedicides and fungicides

iv. Usage of cosmetics

v. Industries Ex; Textile industry, wheat flour mills and asbestos.

vi. Welding, stone crushing, grinding of gem

vii. Natural causes like usage of petroleum solvents in dry cleaning paint, sprays, varnish, etc. that contains

\footnotetext{
${ }^{*}$ Corresponding author

E-mail address: gowripharmajaya@gmail.com
} 
organic solvents which volatilize in the air [1-3].

\section{Air filtration technique}

As a global problem, air pollution produces severe ill effects to human health, hence air filtration technique is extensively used. Various techniques like usage of air conditioned system, portable air cleaners are used for residential air filtration. Air purifier is also called as air cleaners conserve the place clean by removing the pollutants like dust and pollen [4]. Air purifiers contribute great to maintain clean environment since it filter the air contaminants and provide the greater relief to asthmatic and allergic patients .An air purifier is a device (either stand-alone, transportable units or affixed to an "air handler unit") that removes contaminants from the air in an enclosed environment. HEPA (High-efficiency particulate arrestance) was first introduced in the 1950's [5].

\section{Mechanism of action of air purifier [6]}

\subsection{Particles filtration}

HEPA filters capable of removing $0.3 \mathrm{~mm}$ particles with $99.97 \%$ efficiency. It consist of prefilter to eliminate the coarser particles especially against mold spores. HEPA filters made from fiberglass efficiently remove the air contaminants.

\subsection{UV technology}

Thermodynamic sterilization is the process of killing microorganism by burning by the destruction of DNA. A UV air purifier can transform molecules of oxygen and water from air into ozone and hydroxyl compound. The active molecules react with the air pollutants hence destroyed and finally converted into harmless components like water and carbon dioxide [6].

\subsection{Activated carbon technology}

Volatile organic compounds like formaldehyde, benzene and methylene chloride are basically air borne in room temperature leads to consequential damage to kidney, liver, lungs and entire nervous system. Activated carbon consists of many molecular sized pore with high absorbent ability and chemical bonding. It captures air pollutants like gases, tobacco smoke, bad odors and chemical emissions effectively [7-9].

\subsection{Negative ion technology}

Chemical injections are used by negative ion purifiers to clean the air. Air borne particles are taken by the negative ions and transformed in to walls. Negative ions the air by magnetically attracting to pollutants until these newly-formed larger particles become too heavy to remain in the air we breathe $[10,11]$.

\subsection{Ozone generators}

It produces ozone, which is a strong oxidant gas capable of oxidizing chemicals [12].

\section{Control of indoor air pollution}

Channel for outdoor air consists of joints and cracks in walls, floors, ceilings around windows and doors. Volatile organic compounds may be released by various sources including paints, glues, resins, polishing materials, perfumes, spray propellants and cleaning agents. Formaldehyde is a component of some household products which irritate the eyes, nose and airways. To control the indoor air temperature proper ventilation and shading is needed. Hence natural ventilation is achieved by opening windows and doors, gas stove is well ventilated, avoiding smoking inside house. Encase the pillows, mattresses, and box springs in dust-mite-proof covers. Indoor air pollution may arise from the use of open fires, unsafe fuels or combustion of biomass fuels, coal and kerosene [13-14].

\section{Effect of indoor plants}

Indoor plants remove pollutants from the air by absorbing the gases through their leaves and roots Benzene (found in some plastics, fabrics, pesticides and cigarette smoke) and formaldehyde (found in some cosmetics, dish detergent, fabric softener and carpet cleaner) are common examples of common indoor VOCs which can be efficiently eliminated by the plants. The mechanism behind is the microorganisms which live in the soil of potted plants plays significant role 
in neutralizing VOCs and other pollutants. Plants most useful in removing VOCs include Japanese royal ferns, spider plants, Boston ferns, purple waffle plants, English ivy, areca palms, golden pothos, aloe vera, snake plants and peace lilies [15].

Table 1 Indoor plants suitable for air pollution control [16-19]

\begin{tabular}{lll}
\hline Name of the plant & Family & Growth habit \\
\hline Dypsis lutescens & Araceae & Erect, small \\
Orchid (Dendrobium) & Orchidaceae & Small plant \\
Aloe vera & Xanthorrhoeaceae & Small plant \\
Spathiophyllum & Areceae & Small palm \\
Chlorophytum comosum & Liliaceae & Medium plant \\
Nephrolepis obliterata & Lomariopsidaceae & Small plant \\
Hedera helix & Araliaceae & Vigorous climber \\
\hline
\end{tabular}

Large number of houseplants clean indoor air. Bamboo palm, rubber plant, dracaena, spider plant, peace lily and golden pothos. Formaldehyde, reasonable for home pollutant was effectively removed by Boston fem plant and peace lily eliminates acetone [20].

\section{Diseases caused by indoor air pollution}

Over 3.8 million people a year die prematurely from illness owed to the household air pollution induced by the inefficient use of solid fuels and kerosene for cooking. Among these 3.8 million deaths:

- $27 \%$ are due to pneumonia

- $18 \%$ from stroke

- $27 \%$ from ischemic heart disease

- $20 \%$ from chronic obstructive pulmonary disease (COPD)

- $8 \%$ from lung cancer [21]

Particulate matter smaller than 2.5 micrometers is responsible of triggering a chain of reactions (including oxidative stress, inflammation, autonomic imbalance etc.). This may be the prime cause to "vasoconstriction, endothelial dysfunction, increased blood pressure (BP) and heart rate, myocardial ischemia, impaired heart rate variability (HRV), repolarization abnormalities, arrhythmias, and enhanced thrombotic and coagulation potential. Longer-term exposures have been linked to the chronic progression of atherosclerosis as well as the increased incidence of hypertension and diabetes mellitus" [22].

\section{Benefits of air purifier}

\subsubsection{Air purifiers remove triggers for asthma attacks}

Air purifier are capable of eliminating microscopic level impurities. Asthmatic trigger factors like dirt, dust, carbon monoxide, air freshening sprays, hairsprays, smoke from cooking, paints, cosmetics, mold spores, new carpets are effectively removed by air purifier and protect us from disease like asthma [23].

\subsubsection{Air purifiers trap tobacco and cigarette smoke, preventing lung disease}

Encasing smoke with air purifiers with HEPA filters and activated carbon are gaining more popular nowadays since inhaling of tobacco smoke cause chronic obstructive pulmonary diseases and heart diseases. Breathing in tobacco smoke can result in the development of chronic obstructive pulmonary diseases as well as heart disease. Elderly people are at a higher risk of dementia due to exposure of secondhand smoke. HEPA filters can remove tobacco smoke $0.3 \mu$ and cigarette smoke from 4-0.1 $\mu$ [24]. 


\subsubsection{Air purifiers eliminate radon gas:}

Radon gas is produced from natural combination of uranium in soil, rock and water and inhalation of Radon gas cause lung cancer. It enters home through cracks in floors and wall, electrical wire and sump pits. Air purifier protects from lung cancer by eliminating the toxic radon gas [25].

\section{Conclusion}

Clean air is not only important, but foremost requirement to all. Indoor air pollution ranks top five public health threats. Air purifiers are deigned to clean the indoor air by particulate matter filtering mechanism like dust, pollen and gaseous pollutants like hydrocarbons. Air purifiers are considered as life savers since many disease occur due to VOC', molds and improper ventilation at home and it reduces carbon dioxide levels in our home. Natural air purifiers include free ventilation to home, avoiding paraffin candles, using air purifier plants can reduce the risk of indoor air pollution. Indoor plants perform the function of natural living air purifiers since the foliage and roots can absorb the chemical pollutants.

\section{Compliance with ethical standards}

\section{Acknowledgments}

The authors are thankful to Principal Prof. A. Maheswaran, Jaya College of Pharmacy for providing the necessary facilities in the Colleges to carry out the work.

\section{Disclosure of conflict of interest}

There are no conflict of interest.

\section{References}

[1] Choudhary MP and Garg Vaibhaw. (2013). Causes, Consequences and Control of Air Pollution. https://www.researchgate.net/publication/279202084 Causes Consequences and Control of Air Pollution.

[2] Pope CA III and Dockery DW. (2006). Health effects of fine particulate air pollution: lines that connect. Journal of the Air and Waste Management Association, 56(6), 709-742.

[3] Gantz Carroll. (2012). The vacuum cleaner: A history. McFarland, 128.

[4] Eggleston PA. (2005). Improving indoor environments: reducing allergen exposures. The Journal of Allergy and Clinical Immunology, 116(1), 122- 6.

[5] Cesaroni G, Forastiere F, Stafoggia M, Andersen ZJ, Badaloni C, Beelen R, Caracciolo B, de Faire U, Erbel R, Eriksen KT and Fratiglioni L. (2014). Long term exposure to ambient air pollution and incidence of acute coronary events: Prospective cohort study and meta-analysis in 11 European cohorts from the ESCAPE project. British Medical Journal, 348, f7412.

[6] Glover NJ. (2002). Countering chemical and biological terrorism. Civil Engineering, 72(5), 62.

[7] Zeitner WA and Tompkins DT. (2005). Shedding light on photocatalysis. Ashrae Transactions, 111(2), $523-534$.

[8] Ao CH and Lee SC. (2004). Combination effect of activated carbon with TiO2 for the photodegradation of binary pollutants at typical indoor air level. Journal of Photochemistry and Photobiology A: Chemistry, 161(2-3), 131140.

[9] Elliott CG, Colby TV, Kelly TM and Hicks HG. (1989). Charcoal lung: bronchiolitis obliterans after aspiration of activated charcoal. Chest, 96(3), 672-674.

[10] Daniels SL. (2002). On the ionization of air for removal of noxious effluvia. IEEE Transactions on Plasma Science, $30,1471-1481$.

[11] Grabarczyk Z. (2001). Effectiveness of indoor air cleaning with corona ionizers. Journal of Electrostatics, 51-52, 278-283.

[12] Hogan J. (2004). Smog-busting paint soaks up noxious gases. New Scientist, 4. 
[13] UNICEF and World Health Organization. (2002). Children in the new millennium: environmental impact on health.

[14] Desai MA, Mehta S and Smith KR. (2004). Indoor smoke from solid fuels. Assessing the environmental burden of disease at national and local levels. Environmental Burden of Disease Series, 4.

[15] Kim KJ, Jeong MI, Lee DW, Song JS, Kim HD, Yoo EH, Jeong SJ, Han SW, Kays SJ, Lim YW and Kim HH. (2010). Variation in formaldehyde removal efficiency among indoor plant species. HortScience, 45(10), 1489-1495.

[16] Kapoor M. (2017). Managing ambient air quality using ornamental plants-an alternative approach. Universal Journal of Plant Science, 5(1), 1-9.

[17] Wood RA. (2003). Improving the indoor environment for health, well-being and productivity. Greening Cities: a new urban ecology, 30.

[18] Lohr VI, Pearson-Mims CH, Goodwin GK. (1996). Interior plants may improve worker productivity and reduce stress in a windowless environment. Journal of Environmental Horticulture, 14(2), 97-100.

[19] Orwell RL, Wood RL, Tarran J, Torpy F and Burchett MD. (2004). Removal of benzene by the indoor plant/substrate microcosm and implications for air quality. Water, air, and soil pollution, 157(1-4), 193-207.

[20] Cristiano G, Murillo-Amador B and De Lucia B. (2016). Propagation techniques and agronomic requirements for the cultivation of Barbados Aloe (Aloe vera (L.) Burm. F.) -A Review. Frontiers in plant science, 7, 1410.

[21] WEO-2017 Special Report. (2017). Energy access outlook, International Energy Agency, (https://webstore.iea.org/weo-2017-special-report-energy-access-outlook).

[22] Morishita M, Thompson KC and Brook RD. (2015). Understanding air pollution and cardiovascular diseases: is it preventable? Current cardiovascular risk reports, 9(6), 30.

[23] Sublett JL. (2011). Effectiveness of air filters and air cleaners in allergic respiratory diseases: A review of the recent literature. Current allergy and asthma reports, 11(5), 395.

[24] The American Cancer Society medical and editorial content team. (2015). Health Risks of Secondhand Smoke, Last accessed 13, November, 2015. http://www.cancer.org/cancer/cancercauses/tobaccocancer/secondhandsmoke.

[25] Oanh NTK and Hung YT. (2005). Indoor air pollution control. In Advanced Air and Noise Pollution Control. Humana Press, 237-272.

\section{How to cite this article}

Gowri R, Balaji P, Leela Priyanka C, Kamalesh RGK, Jenifer S, Monica K and Vinoth S. (2019). Review on air purifier. GSC Biological and Pharmaceutical Sciences, 7(1), 01-05. 